\title{
Live ascaris in urinary bladder: a case report
}

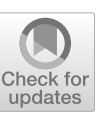

\author{
Gashaw Mesele ${ }^{1}$ and Zelalem Mengistu ${ }^{2^{*}}$ (])
}

\begin{abstract}
Introduction: Ascaris in urinary bladder is an extremely rare phenomenon. It may occur after fistula formation between urinary and gastrointestinal tract or by retrograde migration of adult worm, and is associated with complications.

Case presentation: A 47-year-old Amhara woman from rural northwest Ethiopia presented with a complaint of difficulty to fully evacuate her bladder of 1 year duration. Ultrasonography showed thickened bladder wall with echo debris. There were also thickened bowel and fluid-filled loops of intestine adjacent to urinary bladder. On cystoscopy examination, there was live ascaris swimming inside the bladder. Enterovesical fistula was entertained and explorative laparotomy performed. Findings confirmed presence of iliovesical fistula. The fistula was divided and the continuity of the intestine restored. The inflammatory mass was subjected to histopathology study and turned out to be benign inflammatory reaction. She was also given antihelminthics. Postoperatively, her course was uneventful, and she was discharged cured.
\end{abstract}

Conclusion: Though it is extremely rare to have urinary symptoms from ascariasis, it is important to have a high index of suspicion for all possibilities.

Keywords: Ascaris lumbricoides, Urinary helminthiasis, Urinary ascariasis, Urinary parasites

\section{Introduction}

Soil-transmitted helminth (STH) infections like ascariasis are a public health problem in developing countries where adequate method of disposal of human excreta is not available and affect more than one billion people [1, 2].

People infected with ascaris are often asymptomatic. When it becomes symptomatic, ascariasis presents with myriad of clinical pictures depending on intensity of the infection, the nutritional and immunologic status of the host, and the possible complications that may arise. The sites of involvement are mainly lung during larval migration and intestine after full growth of the helminth. Invasion of the biliary ducts and the liver parenchyma may occur. The adult worm has been reported also in pleural

*Correspondence: emushe10@yahoo.com

2 Department of Obstetrics and Gynecology, University of Gondar, Gondar, Ethiopia

Full list of author information is available at the end of the article cavity, pancreas, peritoneal cavity, lacrimal duct, middle ear, and femoral artery $[3,4]$.

Urinary complications of ascaris are extremely rare [5, 6]. There are very few case reports that are assumed to result from either fistulus communication between the genitourinary system and alimentary canal or due to transurethral access of the worm to the genitourinary system [7]. None of the reports proves the proposed theories; however, in our case, enterovesical fistula formation was clearly demonstrated during laparotomy, which consolidates the theory of fistula formation between the bowel and the urinary system as the reason for finding ascaris in urinary system.

\section{Case presentation}

A 47-year-old para five (all alive and healthy) Amhara woman from rural northwest Ethiopia without remarkable past medical history presented with a complaint of difficulty to fully evacuate her bladder of 1 year duration associated with protruding mass per vagina. Later, she original author(s) and the source, provide a link to the Creative Commons licence, and indicate if changes were made. The images or other third party material in this article are included in the article's Creative Commons licence, unless indicated otherwise in a credit line to the material. If material is not included in the article's Creative Commons licence and your intended use is not permitted by statutory regulation or exceeds the permitted use, you will need to obtain permission directly from the copyright holder. To view a copy of this licence, visit http://creativecommons.org/licenses/by/4.0/. The Creative Commons Public Domain Dedication waiver (http://creativeco mmons.org/publicdomain/zero/1.0/) applies to the data made available in this article, unless otherwise stated in a credit line to the data. 
reported voiding was only possible after reduction of the prolapsed organs. She also reported frequent treatment for urinary tract infection with ciprofloxacillin and norfloxacillin in the last 1 year at a nearby health facility. She has no history of smoking or alcohol consumption. She is a farmer living with her husband and five of her children, and is socially active.

On examination at admission, she was chronically sick looking with normal blood pressure $(110 / 70 \mathrm{mmHg})$, pulse rate ( 88 beats per minute), and temperature $\left(36.5{ }^{\circ} \mathrm{C}\right)$. She had pink conjunctiva, nonicteric sclera, no anterior neck mass, clear and resonant chest, quiet precordium, S1 and S2 heart sound well heard, no murmur or gallop, and flat abdomen without tenderness or palpable mass. On genitourinary examination, she had protruded mass per vagina with uterine cervix as the leading point $6 \mathrm{~cm}$ below the hymenal ring. Otherwise, there were no pertinent positive findings on other parts of her body. On neurologic examination, she had intact sensory and motor function.

On her laboratory tests, her hematocrit was 38\% with normal renal [blood urea nitrogen $(B U N)=20$, creatinin $=0.6$ ] and liver functions (serum glutamic oxaloacetic transaminase $(\mathrm{SGOT})=22$, serum glutamic pyruvic transaminase $(\mathrm{SGPT})=37$ ); human immunodeficiency virus (HIV) test was negative; urine test showed white blood cell (WBC) count more than 10/high-power field (HPF) and there were no ova or parasites on stool examination. On ultrasonography, there was thickened bladder wall with echo debris. There were also thickened bowel and fluid-filled loops of intestine adjacent to urinary bladder (Fig. 1). No radiographic or other scanning was done.

To investigate the bladder mass, we did cystoscopy where we were able to see live ascaris swimming inside

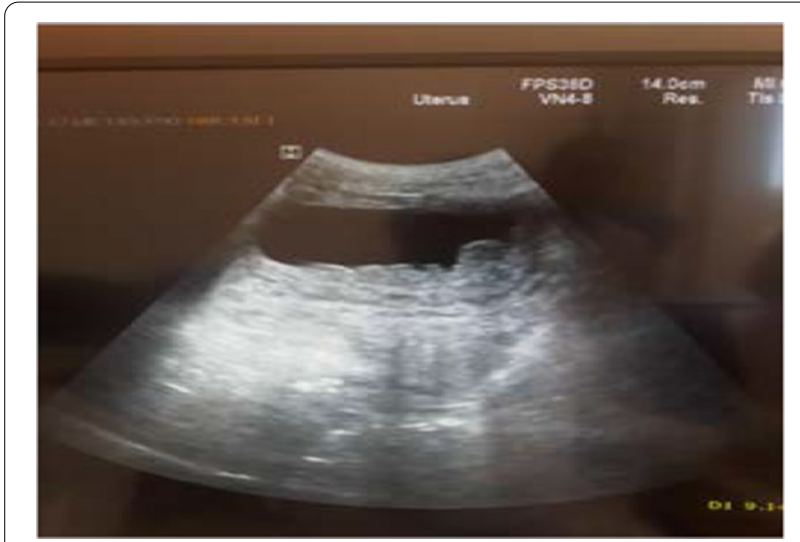

Fig. 1 Thickened bowel and fluid-filled loops of intestine adjacent to urinary bladder the bladder (Fig. 2). It also revealed that there was bladder mucosal edema everywhere and broad-based nonulcerated mass arising from the dome. Enterovesical fistula was entertained and explorative laparotomy performed. Findings confirmed presence of iliovesical fistula (Fig. 3). Mass was of inflammatory origin, and there were no evidence of chronic inflammatory bowel disease of the affected small bowel. The fistula was divided and the continuity of the intestine restored. The inflammatory mass was subjected to histopathology study and turned out to be benign inflammatory reaction. Two weeks later, the pelvic organ prolapse was managed with hysterectomy

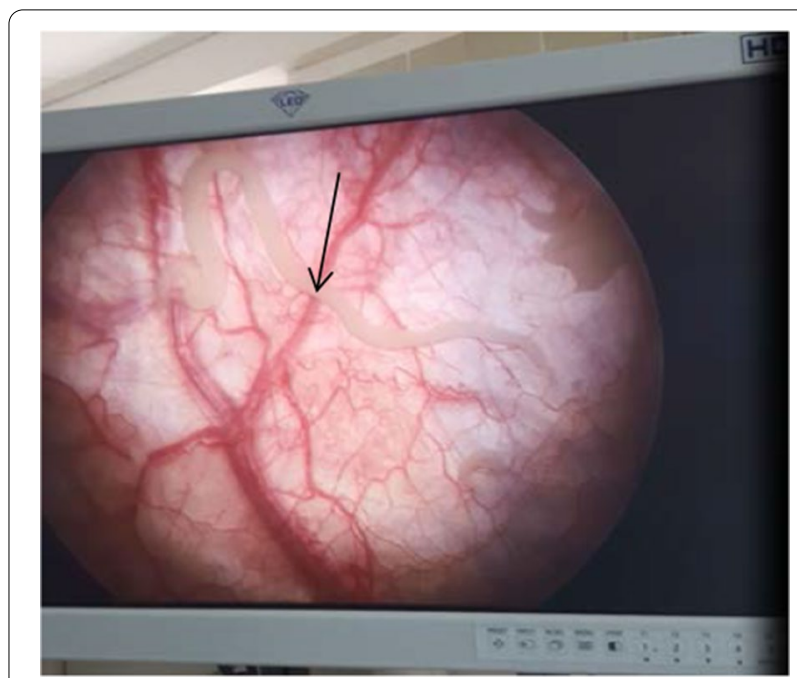

Fig. 2 Live ascaris swimming inside the bladder. Arrow shows swimming Ascaris

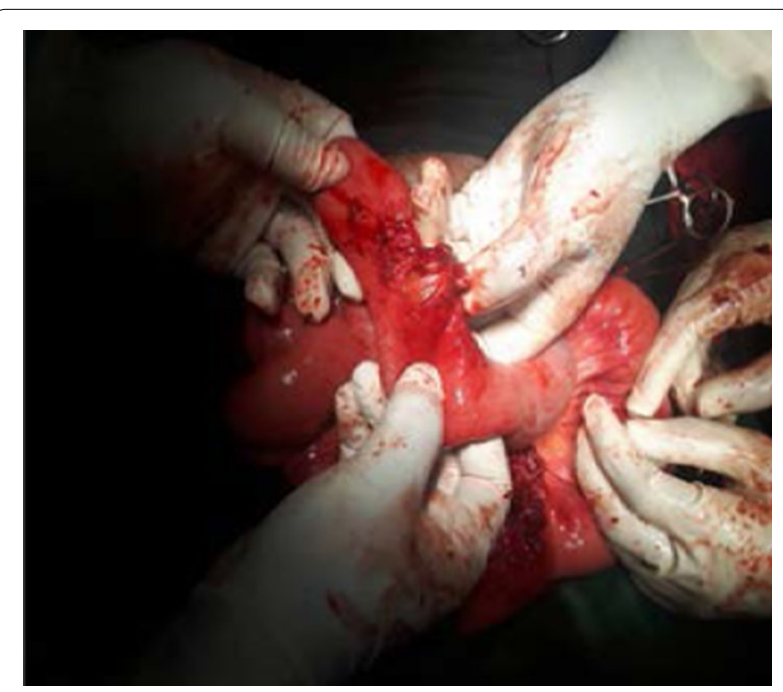

Fig. 3 Perforation of ileum 
and right sacrospinous ligament suspension and bilateral vaginal repair. She was also given albendazole $400 \mathrm{mg}$ po stat and was discharged cured after 3 days of pelvic organ prolapse surgery. She had follow-up after 6 months and was doing fine.

\section{Discussion}

We have presented a women who presented to our facility with difficulty emptying her bladder and protruding mass per vagina of 1 year duration. Ultrasonography was done and showed thickened bladder wall with echo debris and thickened bowel with fluid-filled loops of intestine adjacent to urinary bladder. Thus, cystoscopy was done, which revealed live ascaris swimming in bladder.

Urinary ascariasis (UA) is an extremely rare phenomenon $[5,6]$. UA is assumed to result from either fistula formation between the urinary system and alimentary canal or due to transurethral access of the worm into the urinary system [7]. The most likely explanation for transurethral access might be a worm potentially forced to migrate and exit per anus by deworming therapy, and subsequently moving transperineally to ascend into the urethra and bladder [6]. In our case, the ascaris accessed the bladder through the iliovesical fistula as demonstrated during laparotomy, which supports the theory that fistula formation is a reason for urinary bladder ascariasis, which makes our case peculiar since it was not demonstrated in other case reports so far. There was no other pathology identified in the rest of the bowel; this makes other concomitant systemic pathologies like Crohn's disease, tuberculosis, or malignancy an unlikely cause for the fistula formation. The likely explanation is intestinal perforation due to ascaris, which subsequently elicited inflammation in the bladder, resulting in fistulous communication between bladder and ileum.

\section{Conclusion}

Though it is extremely rare to have urinary symptoms from ascariasis, it is important to have a high index of suspicion for all possibilities, particularly when other possibilities are absent and the patient is not responding to treatments. This case report demonstrated the consequence of ascariasis, emphasizing the need for regular deworming for vulnerable sections of the community, such as farmers.

\section{Abbreviations}

STH: Soil-transmitted helminth; UA: Urinary ascariasis.

\section{Acknowledgements}

None.

Authors' contributions

GM and ZM were responsible for the concept, GM and ZM wrote the paper, and the manuscript was reviewed and edited by GM and ZM. Both authors read and approved the final manuscript.

\section{Funding}

Not applicable.

Availability of data and materials

Not applicable.

\section{Declarations}

Ethics approval and consent to participate

We would like to declare that the need for approval is waived for the case report by our institutional review board (IRB).

\section{Consent for publication}

Written informed consent was obtained from the patient for publication of this case report and accompanying images. A copy of the written consent is available for review by the Editor-in-Chief of this journal.

\section{Competing interests}

The authors declare that they have no competing interests.

\section{Author details}

${ }^{1}$ Department of Surgery, University of Gondar, Gondar, Ethiopia. ${ }^{2}$ Department of Obstetrics and Gynecology, University of Gondar, Gondar, Ethiopia.

Received: 25 February 2021 Accepted: 3 August 2021

Published online: 30 September 2021

\section{References}

1. Montresor A, Mupfasoni D, Mikhailov A, Mwinzi P, Lucianez A, Jamsheed $M$, et al. The global progress of soil-transmitted helminthiases control in 2020 and World Health Organization targets for 2030. PLoS Negl Trop Dis. 2020;14(8):1-17.

2. Pullan RL, Smith JL, Jasrasaria R, Brooker SJ. Global numbers of infection and disease burden of soil transmitted helminth infections in 2010. Parasite Vectors. 2014:7(1):1-19.

3. Khuroo MS, Rather AA, Khuroo NS, Khuroo MS. Hepatobiliary and pancreatic ascariasis. World J Gastroenterol. 2016;22(33):7507-17.

4. Purpurowicz Z, Roslan M, Purpurowicz $Ł$, Ciepliński J. Hematuria from urinary ascariasis. Kidney Int. 2017:91 (6):1521.

5. Gupta P, Sundaram V, Abraham G, Shantha GPS, Mathew M. Obstructive uropathy from Ascaris lumbricoides. Kidney Int. 2009;75(11):1242. https:// doi.org/10.1038/ki.2008.428.

6. Singh D, Vasudeva P, Dalela D, Sankhwar SN. Ascaris lumbricoides: a stranger in the urinary bladder causing urinary retention. J Postgraduate Med. 2010;56:222-3.

7. Baralo B, Gurram S, Steckel J, Chulii M, Sharpilo A. Ascaris in the urinary tract: a case report and review of the literature. Urol Case Rep. 2018;17:82-4. https://doi.org/10.1016/j.eucr.2018.01.003.

\section{Publisher's Note}

Springer Nature remains neutral with regard to jurisdictional claims in published maps and institutional affiliations. 